\title{
Forced Vibration Numerical Analysis of Reticulate Systems by Dynamic Finite Element Method
}

\author{
Olivier A. Passoli ${ }^{1}$, Emmanuel E. T. Olodo ${ }^{1}$, Valery K. Doko ${ }^{1}$, Georges Ale ${ }^{1} \&$ Edmond C. Adjovi ${ }^{1}$ \\ ${ }^{1}$ Laboratory of Energetic and Applied Mechanics (LEMA), University of Abomey-Calavi, Benin \\ Correspondence: Emmanuel E.T. Olodo, Laboratory of Energetic and Applied Mechanics (LEMA), University of \\ Abomey-Calavi, 01BP2009 Cotonou, Benin. Tel: 229-9675-4833. E-mail: olodoe@live.fr
}

Received: February 4, 2019

Accepted: February 24, 2019 Online Published: March 13, 2019

doi:10.5539/mas.v13n4p24

URL: https://doi.org/10.5539/mas.v13n4p24

\begin{abstract}
This work is devoted to forced vibration numerical analysis of reticulate bar systems. The dynamic finite element method was used for determination of frequencies, displacement amplitudes, rotation angles and the dynamic effort factors. By this method the components of the dynamic rigidity matrix and inertia matrix depend on applied external excitation frequency. Obtained results are compared with those calculated by the classical finite element method as well as by analytical method. It is shown that the dynamic finite element allows for exact solutions to the problems in forced vibration of structures. Accuracy of dynamic finite element solution is verified through obtaining analytical solutions on simple systems. In case of complex systems where analytical calculations are complicated the dynamic finite element can become a universal tool for dynamic analysis.
\end{abstract}

Keywords: forced vibrations, numerical analysis, reticulate systems

\section{Introduction}

The reticulate structures can be considered as bar systems which in case when moving loads are applied, dynamic deflections and stresses may become considerably higher than those induced by static loads. Many engineering devices, such as frame structures can be modeled as axially moving bars if the bending stiffness needs to be considered. Under certain excitations axially moving bars undergo the transverse motion. If the motion amplitude is large the nonlinearity needs to be taken into account. Therefore, understanding nonlinear vibrations of axially moving bars is significant for the design of devices.

To solve the problems in forced vibration of reticulate systems several approaches are used. As exact solutions are usually unavailable, approximate analytical methods are widely used to investigate forced vibration of axially moving bars. The used methods include the asymptotic method of Krylov, Bogoliubov and Mitropolsky (Wickert, 1991), the Lindsted-Poincaré method (Pellicano et al., 1997; Chen et al., 2007), the incremental harmonic balance method (Sze et al., 2005) and the method of asymptotic analysis (Wang et al., 2009). In the same order the method of multiple scales is used to investigate forced vibration of axially moving bars with the emphasis on understanding the effects of the mode uninvolved in the resonance (Ghayesh et al.,2010; Chen et al., 2010).To examine the forced vibrations of $1 \mathrm{D}$ beam structure the Timoshenko beam model has been widely adopted to take into account the effects of shear deformation and rotary inertia on the dynamic response (Kim et al., 2017).

Therefore, problems of static and dynamic analysis of free and forced beam vibrations involving complex type of loading cannot be practically solved by analytical methods. Only numerical methods of solution, such as the finite element method, can be efficiently used for the above type of problems. (Arta et al., 2012) and 'Artan et al., 2013) employed the method of initial values to determine the eigenfrequencies and buckling loads respectively, of simple gradient elastic Bernoulli-Euler beams under various boundary conditions at their two ends. Pegios et al., (2018) have recently developed a model for finite element free and forced vibration analysis of gradient elastic beam structures. Mohamed et al., (2018) presented a novel numerical procedure for analysis of nonlinear free and forced vibrations of buckled curved beams resting on nonlinear elastic foundations. (Mehmood, 2015) proposed a work using finite element method vibration analysis of frame structure subject to moving loads. Numerical, experimental and analytical methods have been proposed by (Amin et al., 2014) for free and forced vibration analysis of an infilled steel frame.

However, the disadvantage of using the classical finite element method in the fact that the shape functions used 
are mostly polynomial, do not take into account the vibration frequencies and therefore suggest more or less significant errors on the calculation results. The dynamic stiffness method (Banejee, 2007) which is established in a frequency domain gives exact solutions in free vibration but is not suitable for forced vibration analysis. Under these conditions, the dynamic finite element method which the shape functions take into account eigenfrequencies in free vibration and excitation frequencies in forced vibration, positions itself as a universal structure vibration analysis tool (Olodo et al., 2018).

This work proposes a numerical analysis in forced vibrations of the bar systems by the dynamic finite element method.

\section{Materials and Method}

Consider the bar represented on figure 1 working in traction and compression. Let's assume that this bar is subjected to harmonic excitation of unit amplitude and given pulse $\omega$ :

$$
P(\omega, t)=P_{0} \sin \omega t
$$

$P_{0}=1$ - Unit amplitude

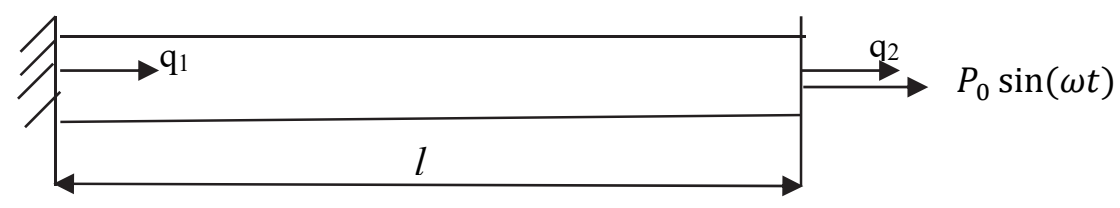

Figure 1. The console bar calculation schema

The movement of the system shown in figure 4.1 is governed by the equation:

$$
u(x, t)=U(z, t) \sin \alpha_{\omega} t=\left(c_{1} \cos \alpha_{\omega} z+c_{2} \sin \alpha_{\omega} z\right) \sin \omega t
$$

Here $\alpha_{m}=\frac{\omega}{a}$.

The boundary conditions are given by:

$$
U(0)=0, E F U^{\prime}(l)=P_{0} \sin \omega t .
$$

By substituting expression (3) in (2) we get the system of equations for the determination of the unknown coefficients $c_{1}$ and $c_{2}$. The resolution of the system gives:

$$
c_{1}=0, c_{2}=\frac{P_{0} a}{E F \omega \cos \alpha_{\omega} l},
$$

And motion equation taking into account the coefficients $c_{1}$ and $c_{2}$ becomes:

$$
u(z, t)=\frac{P_{0} a}{E F \omega \cos \alpha_{\omega} l} \sin \alpha_{\omega} z \sin \omega t .
$$

At the free end of the bar expression (5) takes the following form:

$$
u(l, t)=\frac{P_{0} a}{E F \omega \cos \alpha_{\omega} l} \sin \alpha_{\omega} l \sin \alpha_{\omega} t=\frac{P_{0} a}{E F \omega} \operatorname{tg} \alpha_{\omega} l \sin \omega \omega t .
$$

In expression (6), $\frac{P_{0} a}{E F \omega \cos \alpha_{\omega} l}$ represents the dynamic amplitude of displacement at the considered point. Then express the displacement magnitude as the dynamic amplitude by static displacement report. The bar static displacement under longitudinal force action $P_{0}$ is written by:

$$
A_{s t}=\frac{P_{0} l}{E F} .
$$

In this case relative amplitude of the longitudinal displacement will be:

$$
\frac{A(\omega)}{A_{s t}}=\frac{\operatorname{tg} \alpha_{\omega} l}{\alpha_{\omega} l} \text {. }
$$

Expression (8) is a frequency characteristic of the bar.

Now, the resolution in matrix form problem of forced longitudinal vibrations. Motion matrix equation of forced 
vibration of the system is given by (Diakov et al., 2010):

$$
[M]\{\ddot{Z}\}+[C]\{Z\}=\{P\} .
$$

$\{\ddot{Z}\}$ - Nodal vector acceleration

$\{\mathrm{P}\}$ - vector of nodal forces

For the harmonic excitation (1), we have:

$$
\{P\}=P_{0} \sin \omega t,\{Z\}=Z_{0} \sin \omega t
$$

By substituting the (10) expressions in (9) we get the system of equations of the problem in forced vibration:

$$
\left([C]-\omega^{2}[M]\right)\{Z\}=\{P\} .
$$

The expressions of the dynamic stiffness matrix $\mathrm{C}$ and inertia matrix $M$ for each case in traction, flexion and torsion are established in (Olodo et al., 2018).

The amplitude values of the nodal displacements $\{Z\}$, is determined by resolution of equation system (11):

$$
\{Z\}=\left([C]-\omega^{2}[M]\right)^{-1}\{P\} .
$$

To solve equation (12) it will take into account that the stiffness matrix $[\mathrm{C}]$ and $[\mathrm{M}]$ mass matrix depends on the pulse $\omega$.

The problem in forced vibration of structure represented on figure 1 is solved by the dynamic finite element with the coherent inertia matrix. The results coincide with those obtained analytically to the (8).

\section{Results and Discussion}

\subsection{Traction Bar}

The figure 2 presents the frequency characteristics obtained using the dynamic finite element in $\left(\frac{A(\omega)}{A_{s t}}, \frac{\omega}{k_{1}}\right)$ coordinates, where $A_{s t}$ is the static nodal displacement of unit strength, $k_{1}$ - the first natural frequency of the structure,

$k_{i}=a \propto_{i}$.

\section{Classic Finite Element Method Classic Finite Element Method}

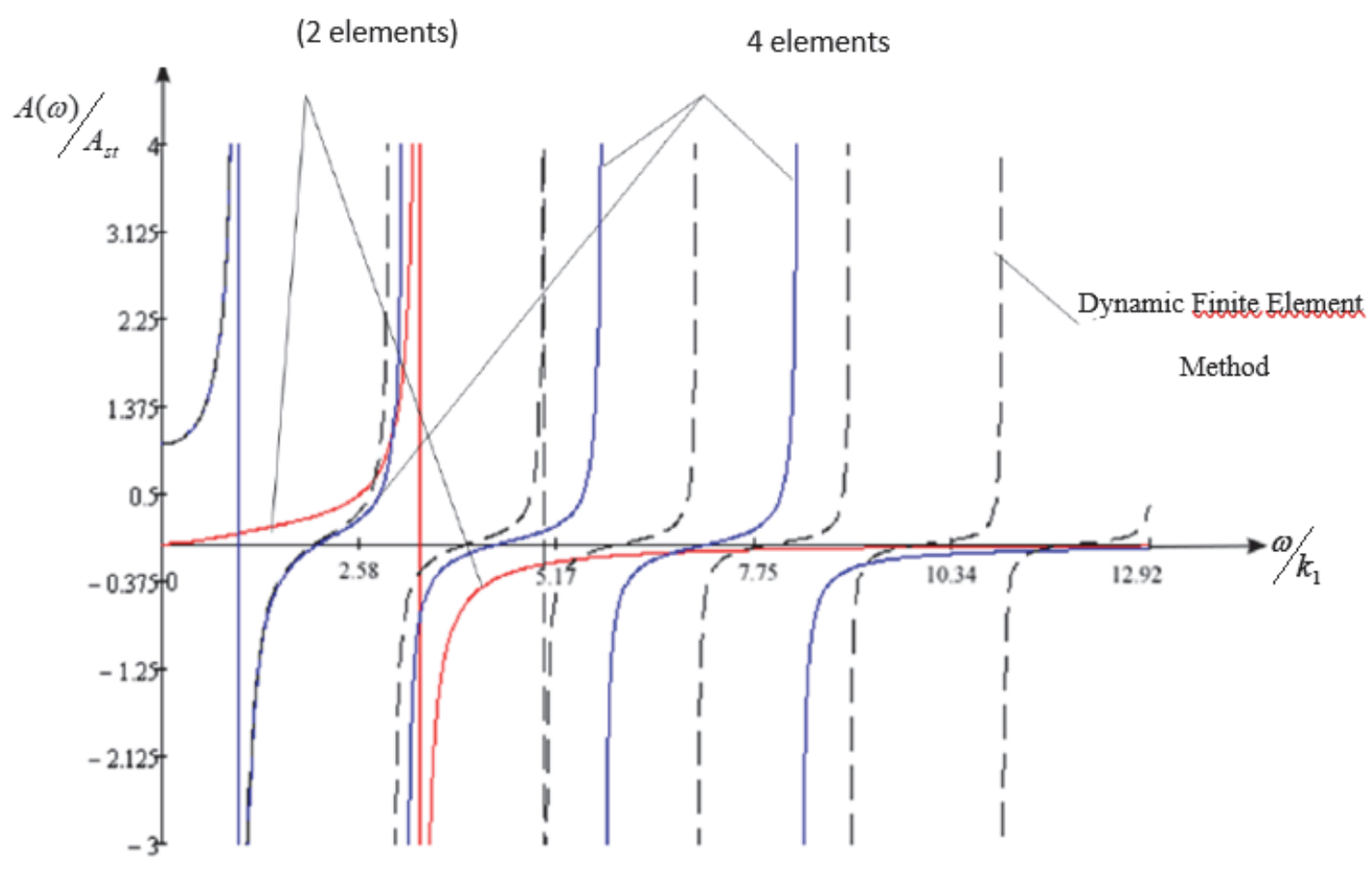

Figure 2. Traction bar frequency characteristics 
In table 1 is presented the comparison of the calculation results in forced vibration by following different methods: analytical method, dynamic finite element method, classic finite element method. For calculations by analytical method and the dynamic finite element method it is shown the parameter values while for classic finite element method indicated the relative error.

Table 1. Frequency and displacement values for the traction bar

\begin{tabular}{|c|c|c|c|c|c|c|}
\hline Parameter & $\begin{array}{c}\text { Frequency } \\
\text { number }\end{array}$ & $\begin{array}{c}\text { Analytical } \\
\text { method }\end{array}$ & $\begin{array}{c}\text { Dynamic Finite } \\
\text { Element Method } \\
\text { (1element) }\end{array}$ & $\begin{array}{c}\text { Classic } \\
\text { Finite } \\
\text { Element } \\
\text { Method } \\
\text { (2 elements) }\end{array}$ & $\begin{array}{l}\text { Classic } \\
\text { Finite } \\
\text { Element } \\
\text { Method } \\
\text { (4 elements) }\end{array}$ & $\begin{array}{l}\text { Classic } \\
\text { Finite } \\
\text { Element } \\
\text { Method } \\
(10 \\
\text { elements) }\end{array}$ \\
\hline$\omega_{\text {res }}$ & 1 & 0,997 & 0,997 & $+237,84 \%$ & $+0,31 \%$ & $+0,25 \%$ \\
\hline \multirow[t]{3}{*}{$\overline{k_{1}}$} & 2 & 2,999 & 2,999 & - & $+5,67 \%$ & $+0,86 \%$ \\
\hline & 3 & 5,000 & 5,000 & - & $+15,21 \%$ & $+2,54 \%$ \\
\hline & 4 & 6,994 & 6,994 & - & - & $+5,09 \%$ \\
\hline$\underline{\omega_{0}}$ & 1 & 2,000 & 2,000 & - & $+2,58 \%$ & $+0,43 \%$ \\
\hline \multirow[t]{3}{*}{$\overline{k_{1}}$} & 2 & 4,000 & 4,000 & - & $+10,25 \%$ & $+1,63 \%$ \\
\hline & 3 & 6,001 & 6,001 & - & $+19,45 \%$ & $+3,71 \%$ \\
\hline & 4 & 8,001 & 8,001 & - & - & $+6,63 \%$ \\
\hline$A\left(0,8 \omega_{r e s}\right)$ & 1 & 2,425 & 2,425 & $-76,277 \%$ & $-0,35 \%$ & $+0,61 \%$ \\
\hline \multirow[t]{3}{*}{$A_{s t}$} & 2 & 0,192 & 0,192 & - & $+13,21 \%$ & $+1,86 \%$ \\
\hline & 3 & 0,00006 & 0,00006 & - & $-100,00 \%$ & $-100,00 \%$ \\
\hline & 4 & 0,084 & 0,084 & - & - & $-28,93 \%$ \\
\hline$A\left(1,2 \omega_{r e s}\right)$ & 1 & 1,670 & 1,670 & $-67,95 \%$ & $+4,67 \%$ & $-0,74$ \\
\hline \multirow[t]{3}{*}{$\overline{A_{s t}}$} & 2 & 0,129 & 0,129 & - & $+34,66 \%$ & $+604 \%$ \\
\hline & 3 & 0,00006 & 0,00006 & - & & $-99,99 \%$ \\
\hline & 4 & 0,054 & 0,054 & - & - & $-42 ? 01 \%$ \\
\hline
\end{tabular}

As can be seen in table 1 the calculation of frequencies and displacement amplitudes gives acceptable accuracy only first resonances regardless of the discretization level of the bar. Similarly in this table we can see that at higher levels of resonance, the error increases sharply. The figure 2 clearly shows a rise in the resonance frequency characteristics. That's why even for a small difference between the values of frequencies obtained by dynamic finite elements and the classic method of finite elements, observed in figure 2 almost parallel sections, which leads to considerable errors on the calculations of the nodal displacements frequencies.

This explanation is not only the traction bars. For other types of loading in bending for example, there will also be an important error not only for calculation of the nodal displacement frequency but also on calculation of angular deformations.

\subsection{Bending Bar}

On figure 3 is presented a bending bar. Vertical harmonic excitation (1) with unit amplitude and given pulse $\omega$ is applied at its free end. 


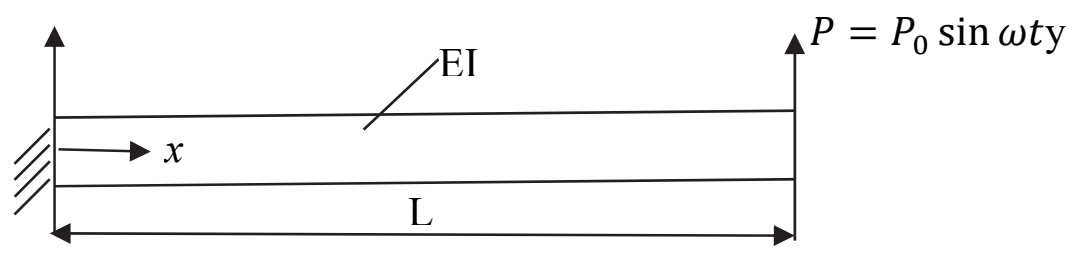

Figure 3. Bending bar calculation schema

The analytical solution in forced vibration for this problem is obtained as follows:

The motion equation is given in following form:

$$
y(x, t)=Y(x) \sin \omega t=\left(c_{1} K_{1}\left(\alpha_{\omega} x\right)+c_{2} K_{2}\left(\alpha_{\omega} x\right)+c_{3} K_{3}\left(\alpha_{\omega} x\right)+c_{4} K_{4}\left(\alpha_{\omega} x\right)\right) \sin \omega t
$$

Here, $K_{1}\left(\propto_{\omega} x\right), K_{2}\left(\propto_{\omega} x\right), K_{3}\left(\propto_{\omega} x\right), K_{4}\left(\propto_{\omega} x\right)$ the Krylov's functions described in (Olodo, et al., 2014),

$\propto_{\omega}=\sqrt[4]{\frac{m_{0} \omega^{2}}{E I}}$

The boundary conditions for the bar of the figure 3 are given by:

$$
Y(0)=0, \quad Y^{\prime}(0), E I Y^{\prime \prime}(l)=0, \quad E I Y Y^{\prime \prime}(l)=P_{o} \sin \omega t
$$

By substituting (14) expressions in (2) it gets the system of equations for determination of unknown coefficients. After the resolution of the system, these coefficients are determined in the following forms:

$$
\begin{gathered}
c_{1}=c_{2}=0, \\
c_{3}=\frac{P_{0} K_{2}\left(\alpha_{\omega} L\right)}{E I a_{w} 3\left(K_{4}\left(\alpha_{\omega} L\right) K_{2}\left(\alpha_{\omega} L\right)-K_{1}^{2}\left(\alpha_{\omega} L\right)\right.}, \\
c_{4}=\frac{P_{0} K_{1}\left(\alpha_{\omega} L\right)}{E I \alpha_{\omega} 3\left(K_{1}{ }^{2}\left(\alpha_{\omega} L\right)-K_{4}\left(\alpha_{\omega} L\right) K_{2}\left(\alpha_{\omega} L\right)\right.} .
\end{gathered}
$$

Taking into account these coefficients, equation (13) becomes:

$$
y(x, t)=\left(\frac{P_{0} K_{2}\left(\alpha_{\omega} L\right) K_{3}\left(\alpha_{\omega} x\right)-P_{0} K_{1}\left(a_{w} L\right) K_{4}\left(\alpha_{\omega} x\right)}{E I \alpha_{\omega}^{3}\left(K_{4}\left(\alpha_{\omega} L\right) K_{2}\left(\alpha_{\omega} L\right)-K_{1}^{2}\left(\alpha_{\omega} L\right)^{\prime}\right.}\right) \sin \omega t .
$$

The equation (18) to the point at the free end will be:

$$
y(L, t)=\left(\frac{P_{0} K_{2}\left(\alpha_{\omega} L\right) K_{3}\left(\alpha_{\omega} L\right)-P_{0} K_{1}\left(\alpha_{\omega} L\right) K_{4}\left(\alpha_{\omega} L\right)}{E I \alpha_{\omega}^{3}\left(K_{4}\left(\alpha_{\omega} L\right) K_{2}\left(\alpha_{\omega} L\right)-K_{1}^{2}\left(\alpha_{\omega} L\right)^{\prime}\right.}\right) \sin \omega t .
$$

As for the case of traction the report in parentheses of expression (19) represents the dynamic amplitude at the point located at the free end of the bar.

Similarly we will express the amplitude of displacements such as the dynamic amplitude by static displacement report.

The static arrow of the bar under vertical load $P_{0}$ will be:

$$
A_{s t}=\frac{P_{0} L^{3}}{3 E I} .
$$

In this case the relative longitudinal amplitude of displacements will take the form below:

$$
\frac{A(\omega)}{A_{s t}}=\frac{3 K_{2}\left(\alpha_{\omega} L\right) K_{3}\left(\alpha_{\omega} L\right)-3 K_{1}\left(\alpha_{\omega} L\right) K_{4}\left(\alpha_{\omega} L\right)}{\alpha_{\omega^{3}} L^{3}\left(K\left(\alpha_{\omega} L\right) K\left(\alpha_{\omega} L\right)-K_{1}{ }^{2}\left(\alpha_{\omega} L\right)\right.}
$$

Expression (4.1.15) represents the frequency characteristic of the bar (figure 3).

The problem in forced vibration of bending bar is resolved by the dynamic finite element and the classic finite element method using the coherent inertia matrix. Dynamic finite element results coincide with those obtained analytically (21).

In table 2 is presented the comparison of calculation results in forced vibration obtained by analytical method, the 
dynamic finite element method and the classic finite element method.

Table 2. Frequency and displacement values for the bending bar

\begin{tabular}{|c|c|c|c|c|c|c|}
\hline Parameter & $\begin{array}{c}\text { Frequency } \\
\text { number }\end{array}$ & $\begin{array}{c}\text { Analytical } \\
\text { method }\end{array}$ & $\begin{array}{l}\text { Dynamic } \\
\text { Finite } \\
\text { Element } \\
\text { Method } \\
\text { (1element) }\end{array}$ & $\begin{array}{c}\text { Classic Finite } \\
\text { Element } \\
\text { Method } \\
\text { (2 elements) }\end{array}$ & $\begin{array}{c}\text { Classic } \\
\text { Finite } \\
\text { Element } \\
\text { Method } \\
\text { (4 elements) }\end{array}$ & $\begin{array}{l}\text { Classic } \\
\text { Finite } \\
\text { Element } \\
\text { Method } \\
\quad(10 \\
\text { elements })\end{array}$ \\
\hline$\omega_{\text {res }}$ & 1 & 0,971 & 0,971 & $+0,00 \%$ & $+0,00 \%$ & $+0,00 \%$ \\
\hline \multirow[t]{3}{*}{$\overline{k_{1}}$} & 2 & 6,229 & 6,229 & $+7,34 \%$ & $+1,83 \%$ & $+1,83 \%$ \\
\hline & 3 & 17,544 & 17,544 & - & $-0,65 \%$ & $+2,28 \%$ \\
\hline & 4 & 34,345 & 34,345 & - & $-4,83 \%$ & $+3,49 \%$ \\
\hline$\underline{\omega_{0}}$ & 1 & 4,385 & 4,385 & $+17,77 \%$ & $-0,49 \%$ & $+0,42 \%$ \\
\hline \multirow[t]{3}{*}{$\overline{k_{1}}$} & 2 & 14,211 & 14,211 & - & $-1,02 \%$ & $+1,27 \%$ \\
\hline & 3 & 29,659 & 29,659 & - & $-5,97 \%$ & $+1,86 \%$ \\
\hline & 4 & 50,708 & 50,708 & - & $-15,66 \%$ & $+1,54 \%$ \\
\hline$A\left(0,8 \omega_{\text {res }}\right)$ & 1 & 2,4808 & 2,4808 & $-0,78 \%$ & $-1,06 \%$ & $-0,57 \%$ \\
\hline \multirow[t]{3}{*}{$A_{s t}$} & 2 & 0,0314 & 0,0314 & $8,08 \%$ & $+10,29 \%$ & $-10,71 \%$ \\
\hline & 3 & $-0,0007$ & $-0,0007$ & $+91,97 \%$ & $-25,78 \%$ & $-80,28 \%$ \\
\hline & 4 & 0,0018 & 0,0018 & - & $+12,31 \%$ & $-22,38 \%$ \\
\hline$A\left(1,2 \omega_{\text {res }}\right)$ & 1 & 2,6730 & 2,6730 & $-2,04 \%$ & $2,16 \%$ & $+1,39 \%$ \\
\hline \multirow[t]{3}{*}{$A_{s t}$} & 2 & 0,0708 & 0,0708 & $-27,46 \%$ & $7,71 \%$ & $-3,85 \%$ \\
\hline & 3 & 0,0098 & 0,0098 & - & $13,27 \%$ & $-0,59 \%$ \\
\hline & 4 & 0,0027 & 0,0027 & - & - & $-6,13 \%$ \\
\hline
\end{tabular}

Calculation results of rotation angle magnitude at the free end are presented in table 3 . The following notations are used in this table:

$\varnothing$ - Rotation angle;

$\emptyset_{s t}$ - Rotation angle for static load of unit force

$\omega_{0}$ - Anti-resonance pulse corresponding to the zero rotation angle

Table 3. Frequency and rotation angle values for bending bar

\begin{tabular}{|c|c|c|c|c|c|c|c|}
\hline Parameter & $\begin{array}{c}\text { Frequency } \\
\text { number }\end{array}$ & $\begin{array}{c}\text { Analytical } \\
\text { method }\end{array}$ & $\begin{array}{l}\text { Dynamic } \\
\text { Finite } \\
\text { Element } \\
\text { Method } \\
\text { (1element) }\end{array}$ & $\begin{array}{l}\text { Classic } \\
\text { Finite } \\
\text { Element } \\
\text { Method } \\
\quad(1 \\
\text { elements })\end{array}$ & $\begin{array}{l}\text { Classic } \\
\text { Finite } \\
\text { Element } \\
\text { Method } \\
\quad(2 \\
\text { elements })\end{array}$ & $\begin{array}{c}\text { Classic } \\
\text { Finite } \\
\text { Element } \\
\text { Method } \\
\text { (4 elements) }\end{array}$ & $\begin{array}{l}\text { Classic } \\
\text { Finite } \\
\text { Element } \\
\text { Method } \\
\quad(10 \\
\text { elements })\end{array}$ \\
\hline$\omega_{\text {res }}$ & 1 & 0,971 & 0,971 & $+0,00 \%$ & $+0,00 \%$ & $+0,00 \%$ & $+0,00 \%$ \\
\hline \multirow[t]{3}{*}{$\overline{k_{1}}$} & 2 & 6,229 & 6,229 & $+7,34 \%$ & $0,00 \%$ & $+1,83 \%$ & $+1,83 \%$ \\
\hline & 3 & 17,544 & 17,544 & - & $-12,38 \%$ & $-0,65 \%$ & $+2,28 \%$ \\
\hline & 4 & 34,345 & 34,345 & - & - & $-4,83 \%$ & $+3,49 \%$ \\
\hline
\end{tabular}




\begin{tabular}{cccccccc}
\hline$\omega_{0}$ & 1 & 2,807 & 2,807 & $+8,44 \%$ & $-1,23 \%$ & $-0,22 \%$ & $+0,06 \%$ \\
$k_{1}$ & 2 & 11,228 & 11,228 & - & $-1,84 \%$ & $-2,04 \%$ & $+0,61 \%$ \\
& 3 & 25,259 & 25,259 & - & - & $-8,30 \%$ & $+0,98 \%$ \\
$\frac{\emptyset\left(0,8 \omega_{\text {res }}\right)}{\emptyset_{\text {st }}}$ & 4 & 44,917 & 44,917 & - & - & $-9,37 \%$ & $+0,34 \%$ \\
& 1 & 2,360 & 2,360 & $+3,085 \%$ & $-0,95 \%$ & $-1,14 \%$ & $-0,59 \%$ \\
& 2 & 0,209 & 0,209 & $-1,843 \%$ & $+8,06 \%$ & $+2,03 \%$ & $+2,85 \%$ \\
$\frac{\emptyset\left(1,2 \omega_{\text {res }}\right)}{\emptyset_{s t}}$ & 3 & 0,037 & 0,037 & - & $-25,83 \%$ & $+11,44 \%$ & $+3,40 \%$ \\
& 1 & 0,009 & 0,009 & - & - & $+122,58 \%$ & $+23,80 \%$ \\
& 2 & 2,369 & 2,369 & $-0,61 \%$ & $+1,73 \%$ & $+2,42 \%$ & $+1,34 \%$ \\
& 3 & 0,168 & 0,168 & $+28,51 \%$ & $+10,28 \%$ & $-6,24 \%$ & $-5,87 \%$ \\
& 4 & 0,029 & 0,029 & - & $+95,71 \%$ & $-22,66 \%$ & $-5,98 \%$ \\
\hline
\end{tabular}

From table 2 and table 3 we can see that error values for determination of the displacement amplitudes at the free end are comparable to those obtained for calculation of rotation angle amplitudes.

The curves of frequency characteristics of the bending bar are presented in figure 4 . On these curves are deferred values obtained by the dynamic finite element method and the classical finite element method. These curves show good convergence of the two methods at the first two resonances, but from the third resonance one observe serious differences on the calculation results.

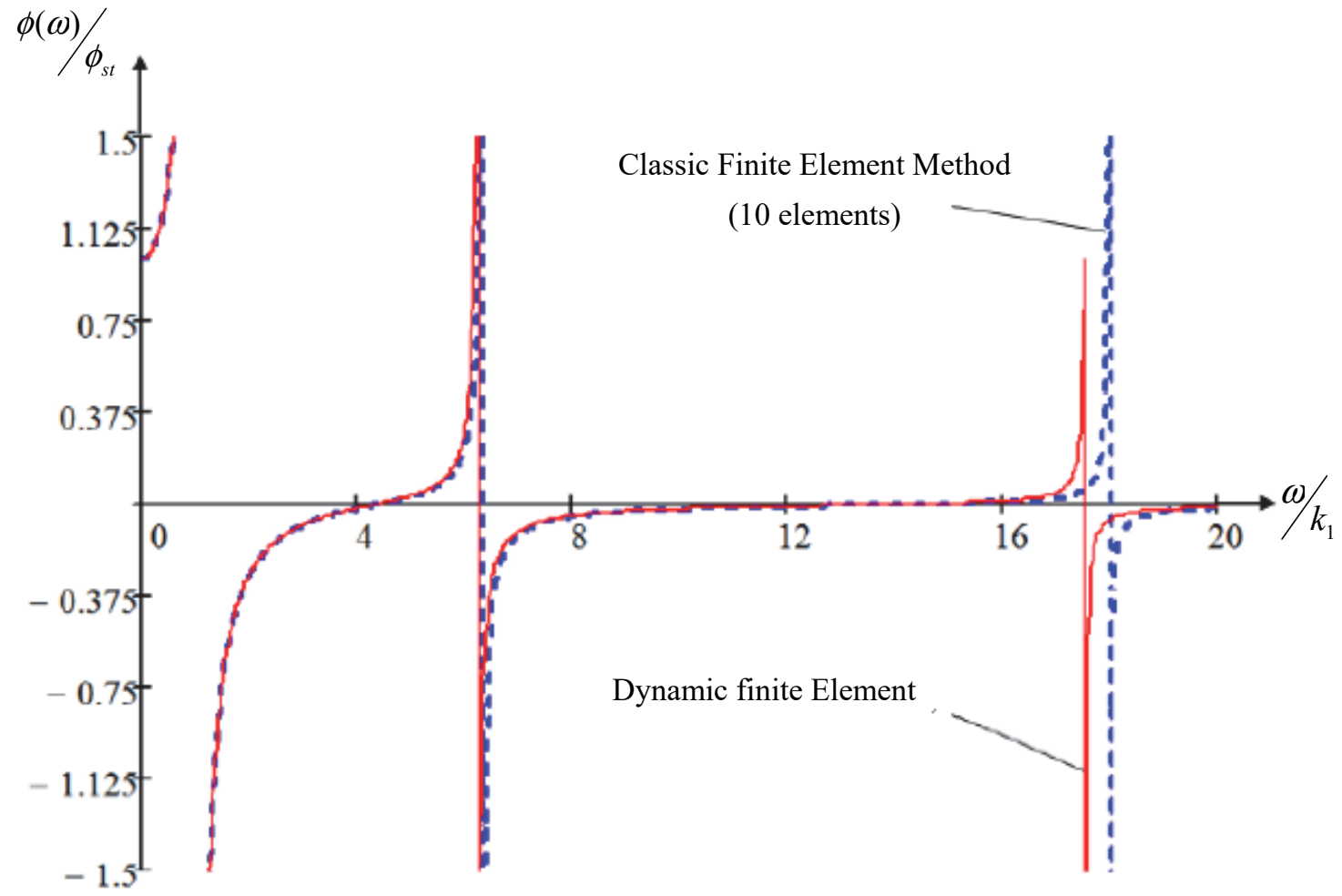




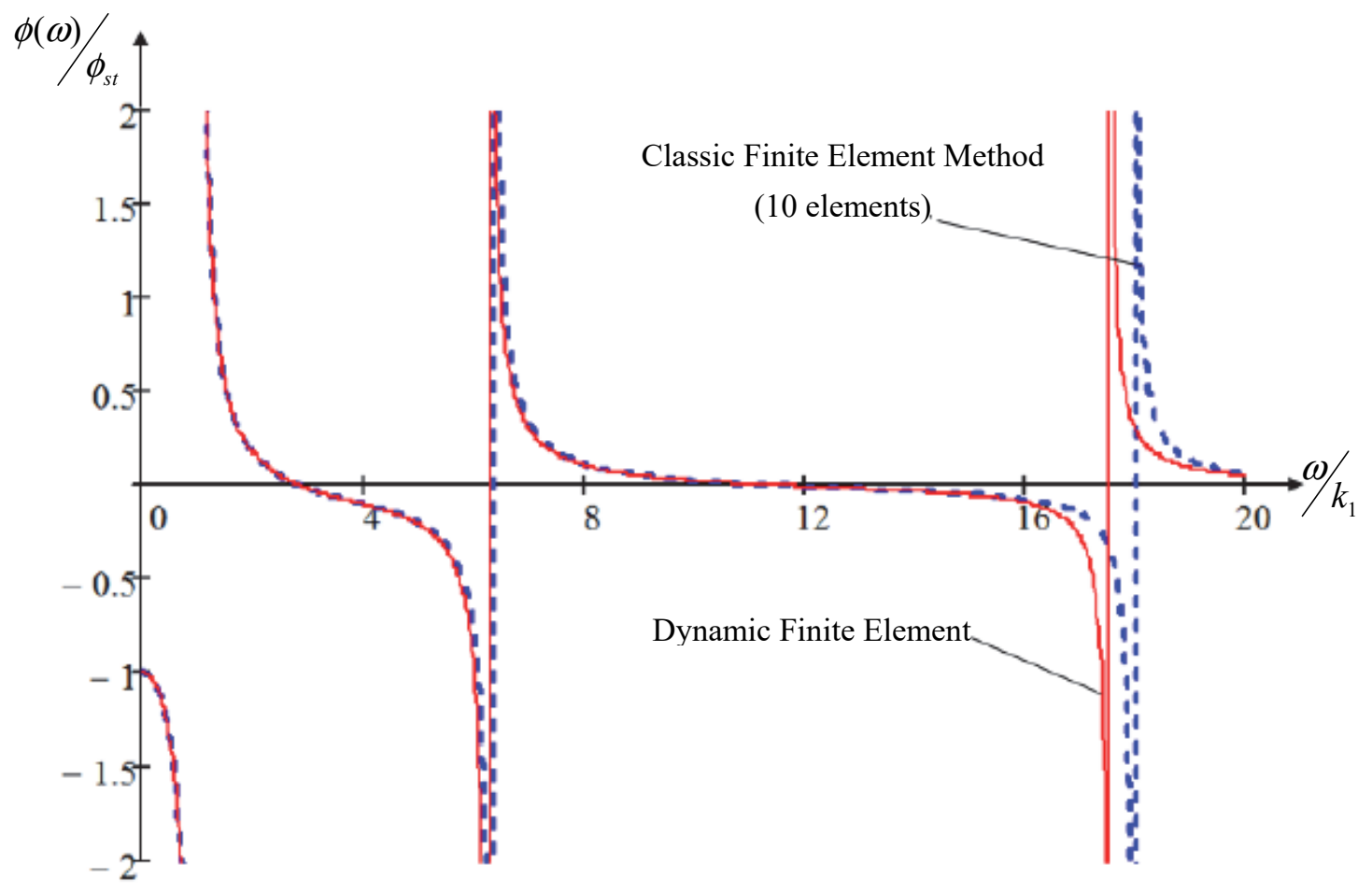

b)

Figure 4. Bending bar frequency characteristics a - displacements, $b$-rotation angle

Thus by a simple example of a bar, comparing calculation results with analytical results, it is shown that dynamic finite element method allows obtaining exact solutions for the dynamic system.

\subsection{Complex Systems}

\subsubsection{Flat Farm}

Consider the flat farm represented on figure 5 which constituting bars work by traction. These bars are of same section and material. In one of its nodes the structure is solicited by harmonic excitation (1) of unit amplitude with frequency $\omega$.

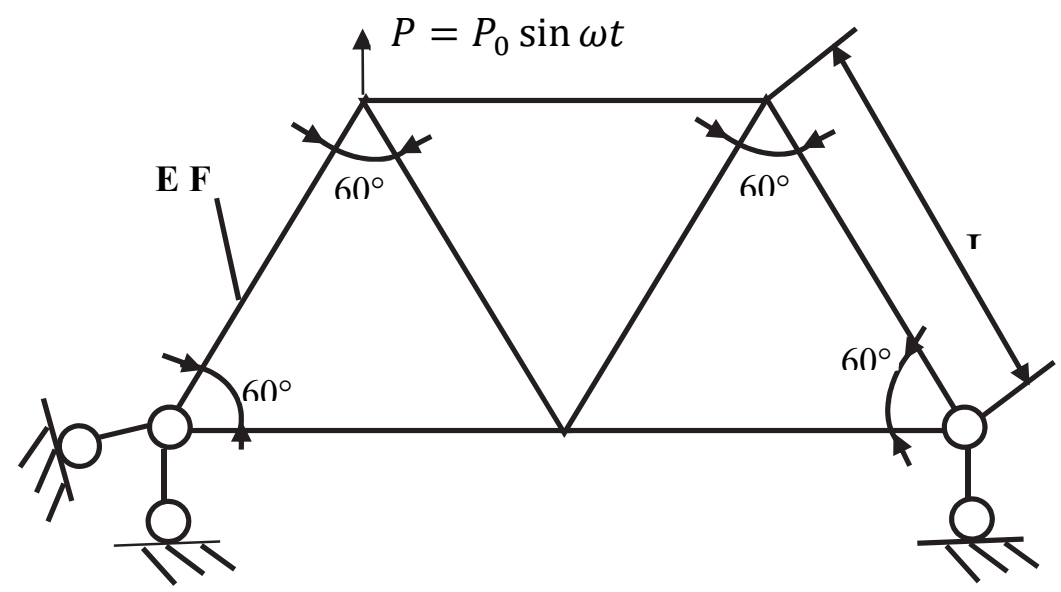

Figure 5. Flat farm calculation scheme

In table 4 are reported the resonance frequency values $\omega_{\text {res }}$ (for displacements equal zero) and displacement 
amplitude values (for $0,8 \omega_{\text {res }}$ and $1,2 \omega_{\text {res }}$ at the node of application of the excitation), $k_{1}$ is determined previously.

Table 4. Frequency and nodal displacement values for flat farm

\begin{tabular}{|c|c|c|c|}
\hline Parameter & $\begin{array}{c}\text { Frequency } \\
\text { number }\end{array}$ & $\begin{array}{c}\text { Dynamic Finite } \\
\text { Element } \\
\text { Method } \\
\text { (1 element })\end{array}$ & $\begin{array}{c}\text { Classic Finite } \\
\text { Element } \\
\text { Method } \\
\text { (1 element) }\end{array}$ \\
\hline \multirow[t]{5}{*}{$\frac{\omega_{\text {res }}}{k_{1}}$} & 1 & 0,991 & $\begin{array}{c}1,00 \\
(+1,11 \%)\end{array}$ \\
\hline & 2 & 1,440 & $\begin{array}{c}1,46 \\
(+1,75 \%)\end{array}$ \\
\hline & 3 & 2,785 & $\begin{array}{c}3,02 \\
(+8,36)\end{array}$ \\
\hline & 4 & 4,060 & $\begin{array}{c}4,71 \\
(+16,12)\end{array}$ \\
\hline & 5 & 6,373 & $\begin{array}{c}7,04 \\
(+10,44 \%)\end{array}$ \\
\hline \multirow[t]{5}{*}{$\frac{\omega_{0}}{k_{1}}$} & 1 & 1,142 & $\begin{array}{c}1,16 \\
(+1,31 \%)\end{array}$ \\
\hline & 2 & 1,835 & $\begin{array}{c}1,90 \\
(+3,43 \%)\end{array}$ \\
\hline & 3 & 3,455 & $\begin{array}{c}3,87 \\
(+11,89 \%\end{array}$ \\
\hline & 4 & 5,625 & $\begin{array}{c}6,70 \\
(+19,02 \%)\end{array}$ \\
\hline & 5 & 5,156 & - \\
\hline \multirow[t]{5}{*}{$\frac{A\left(0,8 \omega_{\text {res }}\right)}{A_{s t}}$} & 1 & 1,717 & $\begin{array}{c}1,73 \\
(+0,95 \%)\end{array}$ \\
\hline & 2 & 0,102 & $\begin{array}{c}0,14 \\
(+42,46 \%)\end{array}$ \\
\hline & 3 & 0,532 & $\begin{array}{c}0,68 \\
(+27,28 \%)\end{array}$ \\
\hline & 4 & 0,275 & $\begin{array}{c}0,09 \\
(-67,65 \%)\end{array}$ \\
\hline & 5 & 0,038 & $\begin{array}{c}0,35 \\
(+823,67 u ̀)\end{array}$ \\
\hline \multirow[t]{3}{*}{$\frac{A\left(1,2 \omega_{\text {res }}\right)}{A_{s t}}$} & 1 & 0,424 & $\begin{array}{c}0,40 \\
(-6,63 \%)\end{array}$ \\
\hline & 2 & 0,241 & $\begin{array}{c}0,30 \\
(+26,35 \%)\end{array}$ \\
\hline & 3 & 0,137 & $\begin{array}{c}0,25 \\
(+83,03 \%)\end{array}$ \\
\hline
\end{tabular}




\begin{tabular}{ccc}
\hline 4 & 0,176 & 0,34 \\
& & $(+90,32 \%)$ \\
5 & 0,222 & 0,16 \\
& & $(-29,46 \%$ \\
\hline
\end{tabular}

In the case of dynamic finite element method calculation, each structure bar is modeled by a single finite element while in the case of the classic method each bar is discretized by a finite element and \% errors are indicated in parentheses.

Static displacement $A_{s t}$ to the loading node is determined by Castiliano theorem:

$$
A_{s t}=\frac{46 P_{0} L}{27 E F} .
$$

In table 4 we see that calculation convergence by the classical finite element method for flat farm is superior to the convergence of similar calculation for the bar. This is due to fact that flat farm has freedom degree number superior to that of the bar.

However the displacement calculation error by the classical finite element method remains high even for a relatively small difference in frequencies. Thus for a $1.75 \%$ difference between value of the second resonance frequency and its exact value, the displacement amplitude values to the node are different their exact values of almost 1.5 times.

\subsubsection{Portico}

Consider now the portico represented on figure 6 and working in flexion. At the free end of the portico is applied harmonic excitation (1) of unit amplitude.

Static displacement $A_{s t}$ at the loading node is determined by Castiliano theorem:

$$
A_{s t}=\frac{P_{0} L_{2}^{3}}{3 E I}+\frac{P_{0} L_{2}^{3} L_{1}}{E I} .
$$

The first portico natural frequency $k_{1}$, as in the case of flat farm is determined previously.

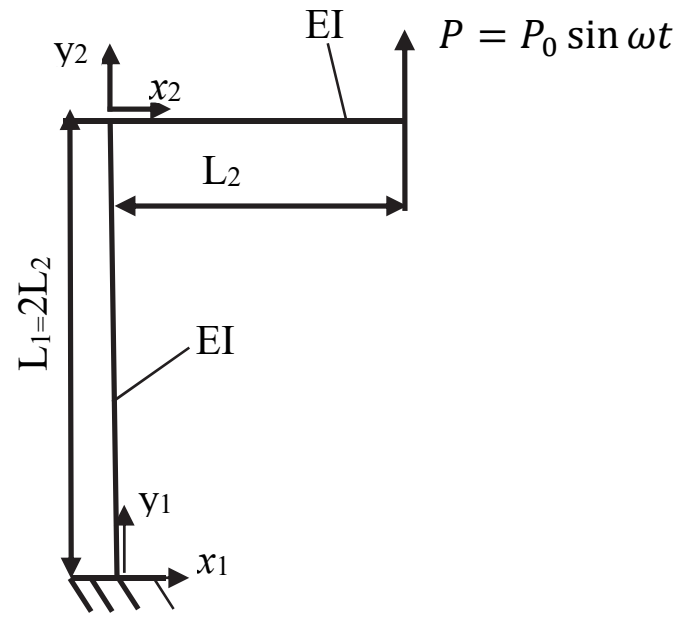

Figure 6. The portico calculation schema in bending

The portico bars are the same section and material but different lengths.

The comparison of the portico calculation results in forced vibration is presented in table 5 . In this table are given the resonance frequency values $\omega_{\text {res }}$, the anti-resonance frequency values $\omega_{0}$ (for displacements equal zero) and the displacement amplitude values (for frequencies $0,8 \omega_{\text {res }}$ and $1,2 \omega_{\text {res }}$ at the node of excitation application). For dynamic finite element calculations, each bar of the portico is modeled by a single finite element. For calculations by the classical finite element method each bar is discretized in one, two and three elements. In table 
5 related errors in $\%$ are indicated in brackets for the classical finite element method.

Table 5. Portico calculation results in flexion

\begin{tabular}{|c|c|c|c|c|c|c|}
\hline Parameter & $\begin{array}{c}\text { Frequency } \\
\text { number }\end{array}$ & $\begin{array}{c}\text { Analytical } \\
\text { Method }\end{array}$ & $\begin{array}{l}\text { Dynamic } \\
\text { Finite } \\
\text { Element } \\
\text { Method }\end{array}$ & $\begin{array}{l}\text { Classic Finite } \\
\text { Element } \\
\text { Method } \\
\text { (1 element) }\end{array}$ & $\begin{array}{c}\text { Classic Finite } \\
\text { Element } \\
\text { Method } \\
\text { (2 elements) }\end{array}$ & $\begin{array}{l}\text { Classic Finite } \\
\text { Element } \\
\text { Method } \\
\text { (3 elements) }\end{array}$ \\
\hline$\omega_{\text {res }}$ & 1 & 0,847 & 0,847 & $+33,33 \%$ & $+16,67 \%$ & $+16,67 \%$ \\
\hline \multirow[t]{3}{*}{$\overline{k_{1}}$} & 2 & 4,304 & 4,304 & $+11,48 \%$ & $+18,03 \%$ & $+21,31 \%$ \\
\hline & 3 & 12,137 & 12,137 & $+110,00 \%$ & $+21,40 \%$ & $+22,79 \%$ \\
\hline & 4 & 28,366 & 28,366 & - & $+10,75 \%$ & $+2,49$ \\
\hline$\omega_{0}$ & 1 & 2,242 & 2,242 & $+48,03 \%$ & $+58,33 \%$ & $+63,13 \%$ \\
\hline \multirow[t]{3}{*}{$\overline{k_{1}}$} & 2 & 10,852 & 10,852 & $69,04 \%$ & $+13,84 \%$ & $+12,85 \%$ \\
\hline & 3 & 23,726 & 23,726 & - & $+6,77 \%$ & $+3,68 \%$ \\
\hline & 4 & 34,687 & 34,687 & - & $+44,57 \%$ & $+20,13 \%$ \\
\hline$A\left(0,8 \omega_{\text {res }}\right)$ & 1 & 41,606 & 41,606 & $+0,946 \%$ & $-30,60 \%$ & $-22,08 \%$ \\
\hline \multirow[t]{3}{*}{$A_{s t}$} & 2 & 4,200 & 4,200 & $-62,50 \%$ & $-81,53 \%$ & $-85,25 \%$ \\
\hline & 3 & 0,310 & 0,310 & $-124,65 \%$ & $-81,90$ & $-91,29 \%$ \\
\hline & 4 & 0,025 & 0,025 & - & $-86,46 \%$ & $-6,57 \%$ \\
\hline$A\left(1,2 \omega_{\text {res }}\right)$ & 1 & 39,375 & 39,375 & $+13,33 \%$ & $+29,33 \%$ & $-22,67 \%$ \\
\hline \multirow[t]{3}{*}{$A_{s t}$} & 2 & 4,856 & 4,856 & $-29,73 \%$ & $-64,86 \%$ & $-73,05 \%$ \\
\hline & 3 & 0,367 & 0,367 & $-47,93 \%$ & $-49,14 \%$ & $-56,90 \%$ \\
\hline & 4 & 0,014 & 0,014 & - & $+402,38 \%$ & $+242,53 \%$ \\
\hline
\end{tabular}

Calculation results of the rotation angle magnitude at the node of excitation application and the error values computed by classical finite element method are presented in table 6 . The rotation angles for unit static load action are given by:

$$
\emptyset_{s t}=\frac{P_{0} L_{2}^{2}}{E I}+\frac{2 P_{0} L_{2} L_{1}}{E I} .
$$

Table 6. Frequency and rotation angle values of portico working in flexion

\begin{tabular}{|c|c|c|c|c|c|c|}
\hline Parameter & $\begin{array}{c}\text { Frequency } \\
\text { number }\end{array}$ & $\begin{array}{c}\text { Analytical } \\
\text { Method }\end{array}$ & $\begin{array}{l}\text { Dynamic } \\
\text { Finite } \\
\text { Element } \\
\text { Method }\end{array}$ & $\begin{array}{c}\text { Classic Finite } \\
\text { Element } \\
\text { Method } \\
\text { (1 element) }\end{array}$ & $\begin{array}{l}\text { Classic Finite } \\
\text { Element } \\
\text { Method } \\
\text { (2 elements) }\end{array}$ & $\begin{array}{c}\text { Classic Finite } \\
\text { Element } \\
\text { Method } \\
\text { (3 elements) }\end{array}$ \\
\hline & 1 & 0,847 & 0,847 & $+33,33 \%$ & $+16,67 \%$ & $+16,67 \%$ \\
\hline$\omega_{\text {res }}$ & 2 & 4,304 & 4,304 & $+11,48 \%$ & $+18,03 \%$ & $+21,31 \%$ \\
\hline$\overline{k_{1}}$ & 3 & 12,137 & 12,137 & $+110,00 \%$ & $+21,40 \%$ & $+22,79 \%$ \\
\hline \multirow{4}{*}{$\frac{\omega_{0}}{k_{1}}$} & 4 & 28,366 & 28,366 & - & $+10,75 \%$ & $+2,49 \%$ \\
\hline & 1 & 1,763 & 1,763 & $+49,42 \%$ & $+48,51 \%$ & $47,37 \%$ \\
\hline & 2 & 9,439 & 9,439 & $+25,12 \%$ & $+4,29 \%$ & $+2,60 \%$ \\
\hline & 3 & 17,519 & 17,519 & $+149,14 \%$ & $+17,83 \%$ & $+18,44 \%$ \\
\hline
\end{tabular}




\begin{tabular}{ccccccc}
\hline & 4 & 32,015 & 32,015 & - & $+40,54 \%$ & $+17,26 \%$ \\
$\frac{\emptyset\left(0,8 \omega_{\text {res }}\right)}{\emptyset_{\text {st }}}$ & 1 & 16,975 & 16,975 & $+2,062 \%$ & $-20,62 \%$ & $-9,28 \%$ \\
& 2 & 3,500 & 3,500 & $-40,00 \%$ & $-54,80 \%$ & $-58,33 \%$ \\
$\frac{\emptyset\left(1,2 \omega_{\text {res }}\right)}{\emptyset_{\text {st }}}$ & 3 & 0,053 & 0,053 & $+640,21 \%$ & $+307,43 \%$ & $+344,59 \%$ \\
& 4 & 0,165 & 0,165 & - & $-12,92 \%$ & $-46,73 \%$ \\
& 1 & 14,350 & 14,350 & $+18,29 \%$ & $+54,88 \%$ & $-7,32 \%$ \\
& 2 & 3,150 & 3,150 & $-27,78 \%$ & $-57,39 \%$ & $-60,88 \%$ \\
& 3 & 0,210 & 0,210 & $+33,72 \%$ & $-15,11 \%$ & $-18,89 \%$ \\
\hline
\end{tabular}

On basis of obtained results we can deduct as to the case of figure 3 console bar that errors of determination of the displacement amplitudes at the node of excitation application are comparable to the calculation errors of rotation angle amplitudes. Practically, however errors do not vary when we increase the number of finite elements. For assessment of the displacement amplitudes and rotation angles even a small discrepancy between the frequency values can lead to a difference of several orders with accurate results. This aspect has a negative influence on the structures with low rigidity.

\subsection{Assessment of the Dynamic Stresses}

Knowledge of displacement and rotation angles values alone does not fully assess the dynamic resistance of a structure. The dynamic resistance in traction or compression determines only by longitudinal force and the bar transversal section. Longitudinal force amplitude value can be determined by the following expression (Biderman, 1980):

$$
P(x)=\operatorname{EFU}(x)
$$

$\mathrm{U}(\mathrm{x})$ - amplitude function determined from the frequency equation of the bar longitudinal vibration.

In the general case the amplitude function is given by (Biderman, 1980):

$$
U(x)=c_{1} \cos \alpha x+c_{2} \sin \alpha x, \quad \alpha=\sqrt[w]{\frac{P}{E}}
$$

$c_{1}, c_{2}$ - unknown coefficients determined by the boundary conditions.

For the case shown in figure 1, the boundary conditions are expressed as follows:

$$
U(0)=0, P(L)=P_{0}
$$

By substituting expressions (25) and (26) in (27), one determines the coefficients $c_{1}$ et $c_{2}$ :

$$
c_{1}=0, \quad c_{2}=\frac{P_{0}}{E F a \cos \alpha L}
$$

By substituting (28) and (26) in (25) it finally gets the following dynamic longitudinal force expression:

$$
P(x)=\frac{P_{0}}{\cos \alpha L} \cos \alpha x
$$

As seen in expression (29) error on the determination of the dynamic stresses in the case of traction corresponds to error on frequencies and displacements.

In the case of the bending, the dynamic stresses are determined by the bending moment and cutting effort in the section. The dynamic bending moment is given by (Biderman, 1980):

$$
M(x)=E I Y^{\prime \prime}(x),
$$

$\mathrm{Y}(\mathrm{x})$ - amplitude function determined from vibration equation in flexion of the bar. In the general case, the amplitude function is given by the following expression:

$$
Y(z)=C_{1} K_{1}(\propto z)+C_{2} K_{2}(\propto z)+C_{3} K_{3}(\propto z)+C_{4} K_{4}(\propto z)
$$

Unknown constants are determined from the boundary conditions. For the case shown in figure 3 these conditions are as follows: 


$$
Y(0)=0, Y^{\prime}(0)=0, M(L)=0, Q(L)=0
$$

$\mathrm{Q}(\mathrm{x})$ - cutting effort:

$$
Q(x)=E I Y^{\prime \prime \prime}(x)
$$

By substituting expressions (30), (30a) and (32) in conditions (31) and then by solving the equation system with unknown coefficients, we finally get expressions of the effort factors:

$$
\begin{aligned}
& M(x)=\frac{P_{0} K_{2}\left(\alpha_{\omega} L\right) K_{1}\left(\alpha_{\omega} x\right)-P_{0} K_{1}\left(\alpha_{\omega} L\right) K_{2}\left(\alpha_{\omega} x\right)}{\alpha_{\omega}\left(K_{4}\left(\alpha_{\omega} L\right) K_{2}\left(\alpha_{\omega} L\right)-K_{1}^{2}\left(\alpha_{\omega} L\right)\right.} \\
& Q(x)=\frac{P_{0} K_{2}\left(\alpha_{\omega} L\right) K_{4}\left(\alpha_{\omega} x\right)-P_{0} K_{1}\left(\alpha_{\omega} L\right) K_{1}\left(\alpha_{\omega} x\right)}{K_{4}\left(\alpha_{\omega} L\right) K_{2}\left(\alpha_{\omega} L\right)-K_{1}^{2}\left(\alpha_{\omega}\right)}
\end{aligned}
$$

\begin{tabular}{|c|c|c|c|c|c|}
\hline $\begin{array}{l}\text { Element } \\
\text { number }\end{array}$ & Frequency & $\begin{array}{c}\text { Moment } \\
\text { (Dyn. Fin. Elm }\end{array}$ & $\begin{array}{c}\text { Moment } \\
\text { (Classic Fin. } \\
\text { Elm.) }\end{array}$ & $\begin{array}{c}\text { Effort } \\
\text { (Dyn. Fin. } \\
\text { Elem.) }\end{array}$ & $\begin{array}{c}\text { Effort } \\
\text { (Classic Fin } \\
\text { Elm.) }\end{array}$ \\
\hline \multirow{2}{*}{1} & 1 & $-0,115$ & $\begin{array}{c}-0,115 \\
(0,00 \%)\end{array}$ & 27,268 & $\begin{array}{c}27,268 \\
(0,00 \%)\end{array}$ \\
\hline & 2 & 0,086 & $\begin{array}{c}-0,008 \\
(-108,91 \%)\end{array}$ & $-71,51$ & $\begin{array}{c}6,618 \\
(-109,25 \%)\end{array}$ \\
\hline \multirow{3}{*}{2} & 1 & $-0,115$ & $\begin{array}{c}-0,115 \\
(0,00 \%)\end{array}$ & 27,268 & $\begin{array}{c}27,268 \\
(0,00 \%)\end{array}$ \\
\hline & 2 & 0,086 & $\begin{array}{c}0,086 \\
(0,00 \%)\end{array}$ & $-71,51$ & $\begin{array}{c}71,51 \\
(0,00 \%)\end{array}$ \\
\hline & 3 & $-0,893$ & $\begin{array}{c}-0,002 \\
(-99,82 \%)\end{array}$ & 1226 & $\begin{array}{c}2,073 \\
(-99,83 \%)\end{array}$ \\
\hline \multirow{4}{*}{4} & 1 & $-0,115$ & $\begin{array}{l}-0,115 \\
(0,00 \%)\end{array}$ & 27,268 & $\begin{array}{c}27,263 \\
(0,00 \%)\end{array}$ \\
\hline & 2 & 0,086 & $\begin{array}{c}-0,042 \\
(-148,84 \%)\end{array}$ & $-71,51$ & $\begin{array}{c}35,745 \\
(-149,99 \%)\end{array}$ \\
\hline & 3 & $-0,893$ & $\begin{array}{c}-0,028 \\
(-96,86 \%)\end{array}$ & 1226 & $\begin{array}{c}37,797 \\
(-96,92 \%)\end{array}$ \\
\hline & 4 & 0,079 & $\begin{array}{c}0,002 \\
(-97,52 \%)\end{array}$ & $-151,483$ & $\begin{array}{c}-3,683 \\
(-97,57 \%)\end{array}$ \\
\hline \multirow{4}{*}{10} & 1 & 0,115 & $\begin{array}{c}-0,115 \\
(0,00 \%)\end{array}$ & 27,268 & $\begin{array}{c}27,268 \\
(0,00 \%)\end{array}$ \\
\hline & 2 & $-0,086$ & $\begin{array}{c}-0,042 \\
(-148,84 \%)\end{array}$ & $-71,51$ & $\begin{array}{c}35,745 \\
(-149,99 \%)\end{array}$ \\
\hline & 3 & $-0,893$ & $\begin{array}{c}0,008 \\
(-100,91 \%)\end{array}$ & 1226 & $\begin{array}{c}-11,341 \\
(-100,93 \%)\end{array}$ \\
\hline & 4 & 0,079 & $\begin{array}{c}-0,003 \\
(-103,54 \%)\end{array}$ & $-151,483$ & $\begin{array}{c}5,474 \\
(-103,61 \%)\end{array}$ \\
\hline
\end{tabular}

For the bar of figure 3 bending moment takes its maximum value at the fixed support $(\mathrm{x}=0)$. Bending moment amplitude values and the dynamic cutting effort values are reported in table 7.

Table 7. Dynamic effort factor values for the bending bar

As seen in table 7 the classic finite elements method described with sufficient accuracy the dynamic stress state to the first excitation frequency. However at higher levels of resonance the error value is more important on the determination of interior effort factors even for a large number of discretized elements.

For the portico shown in figure 6 amplitude function of each stretch is of the form (30a). The boundary conditions for this will be:

$$
\begin{gathered}
Y_{1}=(0), \quad E I Y_{1}^{\prime}(0)=0 ; \\
Y_{1}\left(L_{1}\right)=Y_{2}(0), \quad E I Y_{1}^{\prime}\left(L_{1}\right)=E I Y_{2}^{\prime}(0), \quad E I Y_{1}^{\prime \prime}\left(L_{1}\right)=E I Y_{2}^{\prime \prime}(0) ; \\
E I Y^{\prime \prime}\left(L_{2}\right)=0 ;
\end{gathered}
$$




$$
\begin{aligned}
& E I Y^{\prime \prime \prime}\left(L_{2}\right)=P_{0} ; \\
& E I Y^{\prime \prime \prime}\left(L_{1}\right)=-m_{0} L_{2} \frac{\partial^{2} y_{1}\left(L_{1}, t\right)}{\partial t^{2}} ;
\end{aligned}
$$

Here $y_{1}(x, t)$ - the solution of motion equation of the bending bar (Biderman, 1980):

$$
y_{1}(x, t)=Y_{1}(x) T(t) .
$$

Taking into account the amplitude function (30a) for each section of the portico and the boundary conditions we can determine the unknown constants and motion equations of each section. On the basis of (30) and (32) can also get expressions of interior effort factors. These effort factors for portico made of two different bars will be:

$$
\begin{gathered}
M_{1}\left(x_{1}\right)=E_{1} I_{1} \alpha_{1}{ }^{2}\left(C_{13} K_{1}\left(\alpha_{1} x_{1}\right)+C_{14} K_{2}\left(\alpha_{1} x_{1}\right)\right. \\
Q_{1}\left(x_{1}\right)=E_{1} I_{1} \alpha_{1} 3\left(C_{13} K_{4}\left(\alpha_{1} x_{1}\right)+C_{14} K_{2}\left(\alpha_{1} x_{1}\right)\right. \\
M_{2}\left(x_{2}\right)=E_{2} I_{2} \alpha_{2}{ }^{2}\left(C_{22} K_{4}\left(\alpha_{2} x_{2}\right)+C_{23} K_{1}\left(\alpha_{2} x_{2}\right)+C_{24} K_{2}\left(\alpha_{2} x_{2}\right)\right. \\
Q_{2}\left(x_{2}\right)=E_{2} I_{2} \alpha_{2} 3\left(C_{22} K_{3}\left(\alpha_{2} x_{2}\right)+C_{23} K_{4}\left(\alpha_{2} x_{2}\right)+C_{24} K_{2}\left(\alpha_{2} x_{2}\right),\right.
\end{gathered}
$$

And the unknown coefficients will be:

$$
\begin{gathered}
C_{13}=\frac{A P_{0} K_{2}\left(\alpha_{2} L_{2}\right)}{E_{2} I_{2} \alpha_{2}^{3}\left(B K_{2}\left(\alpha_{2} L_{2}\right)-D K_{1}\left(\left(\alpha_{2} L_{2}\right)\right)\right.} \\
C_{14}=\frac{P_{0} K_{2}\left(\alpha_{2} L_{2}\right)}{E_{2} I_{2} \alpha_{2}^{3}\left(B K_{2}\left(\omega_{2} L_{2}\right)-D K_{1}\left(\left(\alpha_{2} L_{2}\right)\right)\right.} \\
C_{22}=\frac{P_{0} K_{2}\left(a_{2} L_{2}\right)}{E_{2} I_{2} \alpha_{2}^{3}\left(B K_{2}\left(\alpha_{2} L_{2}\right)-D K_{1}\left(\left(\alpha_{2} L_{2}\right)\right)\right.} \frac{E_{1} I_{1}}{E_{2} I_{2}} \frac{a_{1}}{\alpha_{2}}\left(A K_{2}\left(\alpha_{1} L_{1}\right)+K_{3}\left(\alpha_{1} L_{1}\right)\right) \\
C_{23}=\frac{P_{0} K_{2}\left(a_{2} L_{2}\right)}{E_{2} I_{2} \alpha_{2}^{3}\left(B K_{2}\left(\alpha_{2} L_{2}\right)-D K_{1}\left(\alpha_{2} L_{2}\right)\right)} \frac{E_{1} I_{1}}{E_{2} I_{2}}\left(\frac{\alpha_{1}}{\alpha_{2}}\right)^{2}\left(\left(A K_{1}\left(\alpha_{1} L_{1}\right)+K_{2}\left(\left(\alpha_{1} L_{1}\right)\right.\right.\right. \\
C_{24}=\frac{-P_{0} D}{E_{2} I_{2} \alpha_{2}^{3}\left(B K_{2}\left(\alpha_{2} L_{2}\right)-D K_{1}\left(\alpha_{2} L_{2}\right)\right)}
\end{gathered}
$$

The coefficients $A, B, D$ will be:

$$
\begin{gathered}
A=\frac{K_{1}\left(\alpha_{1} L_{1}\right)-L_{2} \alpha_{1} K_{4}\left(\alpha_{1} L_{1}\right)\left(m_{02} / m_{01}\right.}{L_{2} \alpha_{1} K_{3}\left(\frac{m_{02}}{m_{02}}\right)-K_{4}\left(\alpha_{1} L_{1}\right)} \\
B=\frac{\alpha_{1}}{\alpha_{2}}\left(A K_{2}\left(\alpha_{1} L_{1}\right)+K_{3}\left(\left(\alpha_{1} L_{1}\right) K_{3}\left(\alpha_{2} L_{2}\right)+\frac{E_{1} I_{1}}{E_{2} I_{2}}\left(\frac{\alpha_{1}}{\alpha_{2}}\right)^{2}\left(\left(A K_{1}\left(\alpha_{1} L_{1}\right)+K_{2}\left(\alpha_{1} L_{1}\right) K_{4}\left(\alpha_{2} L_{2}\right)\right.\right.\right.\right. \\
D=\frac{\alpha_{1}}{\alpha_{2}}\left(A K_{2}\left(\alpha_{1} L_{1}\right)+K_{3}\left(\left(\alpha_{1} L_{1}\right) K_{4}\left(\alpha_{2} L_{2}\right)+\frac{E_{1} I_{1}}{E_{2} I_{2}}\left(\frac{\alpha_{1}}{\alpha_{2}}\right)^{2}\left(\left(A K_{1}\left(\alpha_{1} L_{1}\right)+K_{2}\left(\alpha_{1} L_{1}\right) K_{1}\left(\alpha_{2} L_{2}\right)\right.\right.\right.\right.
\end{gathered}
$$

In table 8 are presented the portico effort factor values, values obtained by the dynamic finite element method (one per section) and by the classical finite element method (one to three elements per section). Dynamic finite element results coincide with those of the analytical method.

Table 8. Dynamic effort factor values for the portico

\begin{tabular}{cccccc}
\hline $\begin{array}{c}\text { Element } \\
\text { number }\end{array}$ & Frequency & $\begin{array}{c}\text { Moment } \\
(\text { Dyn. Fin. } \\
\text { Elm.) }\end{array}$ & $\begin{array}{c}\text { Moment } \\
\text { (Classic Fin. Elm.) }\end{array}$ & $\begin{array}{c}\text { Effort } \\
\text { (Dyn. Fin. } \\
\text { Elem;) }\end{array}$ & $\begin{array}{c}\text { Effort } \\
\text { (Classic Fin. Elm.) }\end{array}$ \\
\hline \multirow{2}{*}{1} & 1 & $-1,318$ & $\begin{array}{c}\text { 1st section }\left(x_{1}=\mathrm{L}_{1}\right) \\
-1,366(3,64 \%)\end{array}$ & $-0,717$ & $0,806 \quad(12,41 \%)$ \\
& 2 & $-2,035$ & $-2,084(2,41 \%)$ & $-1,733$ & $-1,765(1,85 \%)$ \\
& 3 & $-0,480$ & $0,023(-104,79 \%)$ & $-0,098$ & $0,165 \quad(268,37 \%)$ \\
& 4 & 0,031 & $0,010(-67,74 \%)$ & 0,149 & $0,02 \quad(-86,58 \%)$ \\
3 & 1 & $-1,318$ & $-1,320(0,15 \%)$ & $-0,717$ & $-0,720(0,42 \%)$ \\
& 2 & $-2,035$ & $-2,073(1,87 \%)$ & $-1,733$ & $-1,737(0,23 \%)$ \\
& 3 & $-0,480$ & $-0,183(-61,88 \%)$ & $-0,098$ & $0,116 \quad(-218,37 \%)$ \\
\hline
\end{tabular}




\begin{tabular}{cccccc}
\hline & 4 & 0,031 & $0,031(0,00 \%)$ & 0,149 & $0,147 \quad(-1,34 \%)$ \\
& 5 & 0,032 & $\begin{array}{c}0,028(-12,50 \%) \\
2^{\text {nd }} \text { section }\left(x_{2}=\mathrm{L}_{1}\right)\end{array}$ & 0,099 & $0,079 \quad(-20,20 \%)$ \\
& & & $-0,650(3,83 \%)$ & 1,307 & $1,342 \quad(2,68 \%)$ \\
& 1 & $-0,626$ & $-1,393(13,53 \%)$ & 1,299 & $1,014 \quad(-21,94 \%)$ \\
& 2 & $-1,227$ & $-0,593(-49,83 \%)$ & $-1,613$ & $-1,270 \quad(-21,26 \%)$ \\
& 3 & $-1,182$ & $-0,43(-22,24 \%)$ & $-1,200$ & $-0,947 \quad(-21,08 \%)$ \\
& 4 & $-0,553$ & $-0,627(0,16 \%)$ & 1,307 & $1,308(0,08 \%)$ \\
& 1 & $-0,626$ & $-1,471(19,89 \%)$ & 1,299 & $0,816(-37,18 \%)$ \\
& 2 & $-1,227$ & $-0,927(-21,57 \%)$ & $-1,613$ & $-1612(-0,06 \%)$ \\
& 3 & $-1,182$ & $-0,550(-0,54 \%)$ & $-1,200$ & $-1,194(-0,50 \%)$ \\
& 4 & $-0,553$ & $-0460(-4,17 \%)$ & $-1,051$ & $-1,004(-4,47 \%)$ \\
\hline
\end{tabular}

In table 8 we can notice that although there is an increase in the convergence of classic finite element solutions with the increase in finite element number, on certain frequencies there are important differences: so the solutions by the finite element method may be divergent exact solutions more twice.

\section{Conclusions}

1. On examples of simple reticulate structures, it is shown that the dynamic finite element method allows for exact solutions to the problems in forced vibration of structures. Accuracy of the dynamic finite element solutions is verified through obtaining analytical solutions on simple systems. In the case of complex systems where the analytical solutions are complicated the dynamic finite element can become a universal tool for dynamic analysis.

2. In the case of dynamic analysis of reticulate structures in forced vibration the components of the dynamic rigidity matrix and inertia matrix of the dynamic finite element method depend on applied external excitation frequency. Remember that in the case of free vibration, the matrices components depend on natural frequency

3. Calculation accuracy of frequencies, displacement amplitudes and rotation angles can only be achieved on the first resonances independently of the discrete element number of the bar. For the higher resonances, even a small difference between the frequencies obtained by both methods led to abrupt increased error on calculation of amplitudes and rotation angles. Such error is due to the fact that the frequency characteristic increases sharply (figure 2).

4. The calculation errors by the classic finite element method in figure 5 and figure 6 are lower than the calculation errors by analytical method in figures 1 and figure 3 . This is due to that the bar systems have many more freedom degrees than a simple bar.

5. Errors on the determination of interior effort factors in traction coincide with the calculation errors on the frequencies and displacements. In the case of bending errors on the calculation by the classic finite element method will decrease with the increase in the finite element number. However, by the classical finite element method there is a good description of the dynamic stress state on the first resonance (table 7). However at higher resonances the classic method presents considerable calculation error on the determination of interior effort factors, even for a large number of discrete elements.

\section{References}

Amin, M. H. A., Samani, R. H., \& Mirtaheri, M. (2014). Free and Forced Vibration analysis of an infilled steel frame. Experimental, numerical and analytical methods. Shok and Vibration, 2014, 1-15.

Artan, R., \& Batra, R. C. (2012). Free vibrations of strain gradient beam by the method of initial values. Acta Mechanica, 223, 2393-2409.

Artan, R., \& Toksoz, A. (2013). Stability analysis of gradient elastic beam by the method of initial values. Archive of Applied Mechanics, 83, 1129-1144.

Banerjee, J. R., Cheung, C. W., Morishima, R., Perera, M., \& Njuguma, J. (2007). Free vibration of a three-layered sandwich beam using the dynamic stiffness method and experiment. International Journal of Solids and Structures, 44, 7543-7563.

Biderman, V. L. (1980). Theory of mechanical vibrations. Vysshaya shkola, Moscow.

Chen, L. Q., Tang, Y. Q., \& Lin, C. W. (2010). Dynamic stability in parametric resonance of axially accelerating 
viscoelastic Timoshenko beams. Journal of Sound and Vibration, 329, 547-565.

Chen, S. H., Huang, J. I., \& Sze, K. Y. (2007). Multidimensional Lindsted-Poincaré method for nonlinear vibration of axially moving beams. Journal of Sound and Vibration, 306, 1-11.

Ghayesh, M. H. (2010). Parametric vibrations and stability of an axially accelerating string guided by a nonlinear elastic foundation. International Journal of Nonlinear Mechanics, 45, 382-394.

Kim, T., Park, I., \& Lee, U. (2017). Forced vibration of a Timoshenko beam subject to stationary and moving loads using the modal analysis method. Shock and Vibration, 2017, 1-27.

Mehmood, A. (2015). Using finite element method vibration analysis of frame structure subject to moving loads. International Journal of Mechanical Engineering and Robotics Research, 4(1), 50-65.

Mohamed, N., Eltaher, M. A., Mohamed, S. A., \& Seddek, L. F. (2018). Numerical analysis of nonlinear free and forced vibrations of buckled curved beams resting on nonlinear elastic foundations. International Journal of Non-Linear Mechanics, 101, 157-173.

Olodo, E. E. T., \& Degan, G. (2014). Construction of the shape functions of beam vibrations for analysis of the rectangular plates by Kantorovich-Vlasov's method. Structural Engineering Mechanics, 52(3), 595-601.

Olodo, E. E. T., Passoli, A. O., \& Adanhounme, V. (2018). Construction of a dynamic finite element model for vibration analysis of reticulate systems. Annals of Faculty Engineering Hunedoara, Tom XVI, Fascicule, 3, 59-67.

Pegios, I. P., \& Hatzigeorgiou, G. D. (2018). Finite element free and forced vibration analysis of gradient elastic beam structures. Acta Mechanica, 229, 4817-4830.

Pellicano, F., \& Zirilli, F. (1997). Boundary layers and non-linear vibration in an axially moving beam. International Journal of Nonlinear Mechanics, 33, 691-711.

Sze, K. Y., Chen, S. H., \& Huang, J. I. (2005). The incremental harmonic balance method for nonlinear vibration of axially moving beams. Journal of Sound and Vibration, 281, 611-626.

Wang, R., \& Chen, I. Q. (2009). Asymptotic stability analysis with numerical confirmation of an axially accelerating beam constituted by the standard linear solid model. Journal of Sound and Vibration, 328, 456466.

Wickert, J. A. (1991). Non-linear vibration of a traveling tensioned beam. International Journal of Nonlinear Mechanics, 27, 503-517.

\section{Copyrights}

Copyright for this article is retained by the author(s), with first publication rights granted to the journal.

This is an open-access article distributed under the terms and conditions of the Creative Commons Attribution license (http://creativecommons.org/licenses/by/4.0/). 